\title{
Lymphocytes sensitivity to Fas stimulation in healthy and asthmatic children
}

\section{Olga Potapińska ${ }^{1}$, Anna Zawadzka-Krajewska ${ }^{2}$, Iwona Kotuła ${ }^{1}$, Beata Pyrżak ${ }^{3}$, Katarzyna Gomułka ${ }^{4}$, Maria Wąsik ${ }^{1}$, Urszula Demkow ${ }^{1}$}

\author{
${ }^{1}$ Department of Laboratory Diagnostics and Clinical Immunology of Developmental Age, \\ Medical University of Warsaw \\ ${ }^{2}$ Department of Pediatric Pneumonology and Allergology, Medical University of Warsaw \\ ${ }^{3}$ Department of Pediatric Endocrinology, Medical University of Warsaw \\ ${ }^{4}$ Department of Laboratory Diagnostics and Clinical Immunology of Developmental Age, \\ Litewska Children's Hospital, Warsaw
}

\begin{abstract}
The T cell hypothesis of asthma is based on the concept that the disease is driven and maintained by the persistence of a specialized subset of chronically activated $\mathrm{T}$ memory cells sensitized against an array of allergenic, occupational or viral antigens. Overreaction of CD4+ T cells in the peripheral blood and airway tissues is an invariant feature of asthma; therefore a potent mechanism for augmenting the number of activated $\mathrm{T}$ cells in this disease would be the resistance to the normally programmed pathway for cell death. The aim of the study was to evaluate the presence of apoptotic markers on peripheral blood lymphocytes from healthy and asthmatic children before and after stimulation with antiCD95 antibodies. The blood was collected from 21 children with atopic asthma suffering from allergic rhinitis because of house dust mite and/or grass pollen allergens and 8 healthy children matched for their age and sex. Blood was mixed with purified monoclonal antibody antiCD95 (Beckman Coulter), incubated for 24 hours and than stained with Annexin V andPI (Becton Dickinson). Prepared suspensions were analyzed with Cytomics FC 500 (Beckman Coulter) flow cytometer. Annexin V(+)/PI(-) cells were characterized as early apoptotic, Annexin $\mathrm{V}(+) / \mathrm{PI}(+)$ as late apoptotic and Annexin $\mathrm{V}(-) / \mathrm{PI}(+)$ as dead. In unstimulated sample from asthmatic children $21.09 \pm 11.20 \%$ cells were characterized as Annexin V positive/PI negative. After stimulation with antiCD95 Annexin V positive/PI negative cells constituted $18.72 \pm 9.42 \%$ of cells, $p=0.1$. In unstimulated sample from healthy children $11.69 \pm 6.70 \%$ cells were characterized as Annexin V positive/PI negative. In the sample stimulated with antiCD95 $16.54 \pm 2.98 \%$ of cells were Annexin V positive/PI negative, $p=0.02$. There were no differences between results of late apoptotic and necrotic lymphocytes from healthy and asthmatic children. Performed research indicates that lymphocytes from asthmatic children are resistant to Fas mediated apoptosis.
\end{abstract}

Key words: Fas-mediated apoptosis, asthma, lymphocytes, flow cytometry, annexin V

\section{Introduction}

Allergic diseases are a result of impaired immunoregulation. The CD4+ T lymphocytes play a major role in the pathogenesis of asthma. They regulate recruitment and activation of airway eosinophils and IgE production [1].

Overreaction of $\mathrm{CD} 4+\mathrm{T}$ cells in the peripheral blood and airway tissues is a main feature of asthma; therefore a potent mechanism for augmenting the

Correspondence: O. Potapińska, Dept. of Laboratory Diagnostics and Clinical Immunology of Developmental Age, Medical University of Warsaw, Marszalkowska Str. 24, 00-576 Warszawa, Poland; tel./fax.: (+4822) 6296517,

e-mail: olga.potapinska@wum.edu.pl number of activated $\mathrm{T}$ cells in this disease would be a resistance to normally programmed pathway for cell death. There are at least 3 different mechanisms by which a cell dies in the course of apoptotic process including triggering of apoptotic signals by death activators binding its ligands at the cell surface e.g. FasL, TNF- $\alpha$. Cell surface's death receptors can transmit apoptotic signals in response to external stimuli such as death ligands, growth factor withdrawal or drugs. Peripheral $\mathrm{T}$ cell death requires the action of death receptor/ligand system, particularly Fas (CD95) and Fas ligand interaction. The interaction between Fas and FasL results in the formation of the death-inducing signaling complex (DISC), which contains the Fasassociated death domain protein (FADD), caspase-8 
and caspase-10. Caspase- 8 activates other members of the caspase family, and triggers the execution of apoptosis [2].

The published data show a selective resistance of activated $\mathrm{T}$ cells to undergo Fas-induced apoptosis in asthmatic in comparison with nonasthmatic control subjects. Because apoptosis of mature T cells is a powerful mechanism for maintaining immunological system's balance, it raises the possibility that unequal apoptosis of T cells subpopulations plays a key role in disturbed immunoregulation in atopic diseases [3].

One of the early stages of apoptosis is the translocation of phosphatidylserine (PS) from the inner side of the plasma membrane to the outer layer, by which PS becomes exposed at the external surface of the cell. Annexin $\mathrm{V}$ is a $\mathrm{Ca}^{2+}$ dependent phospholipids-binding protein with high affinity for PS. Hence this protein can be used as a sensitive probe for PS exposure upon the cell membrane. Therefore the measurement of Annexin $\mathrm{V}$ binding to the cell surface is a measure of early apoptotic process [4].

The aim of the study was to evaluate the presence of apoptotic markers on peripheral blood lymphocytes from healthy and asthmatic children before and after stimulation with antiCD95 antibodies.

\section{Materials and methods}

Patients. The peripheral blood was taken from 21 children with atopic asthma and 8 healthy children matched for their age and sex. Atopy was defined by positive skin prick test and result of specific IgE evaluation. Patients were sensitized to grass pollen and/or house dust mite antigens. Healthy individuals were characterized by negative quantitative IgE test and negative history of asthma. They were chosen from children with no systemic illness or recent respiratory illness. One milliliter of blood was taken by venipuncture from each individual to tubes containing EDTA for complete blood count test. Remaining material was used for the flow cytometry. The study was approved by the Ethics Commission of Medical University of Warsaw. The parents of included children gave informed consent for participation in the study.

AntiCD95 stimulation. $200 \mu$ of whole blood was transmitted to sterile tubes and mixed with $20 \mu \mathrm{l}$ of purified monoclonal antibody antiCD95 (Beckman Coulter) in concentration of $0.2 \mathrm{mg} / \mathrm{ml}$. For evaluation of spontaneous apoptosis $200 \mu \mathrm{l}$ of whole blood from the same patient was transmitted to sterile tubes and mixed with 20 $\mu 1$ of phosphate buffered saline (PBS). Tubes were incubated for 24 hours in $37^{\circ} \mathrm{C}, 5 \% \mathrm{CO}_{2}$. humidity $95 \%$.

Annexin V and propidium iodide labeling. $100 \mu \mathrm{l}$ of whole blood from each tube was transmitted to different cytometric tubes. Erythrocytes were lysed with $1 \mathrm{ml}$ of Lysing Solution (Becton Dickinson) for 20 minutes in RT (room temperature), in the dark. The staining was accordant to the manufacturer of Annexin V Kit procedure (Becton Dickinson). Leukocytes were washed twice with cold PBS, resuspended in $100 \mu 1$ of Binding Buffer, stained with $5 \mu$ l of Annexin V and $5 \mu$ of PI, incubated for 15 minutes in the dark in RT and resuspended in $400 \mu \mathrm{l}$ of Binding Buffer.

Flow cytometric analysis. Prepared suspensions were analyzed with Cytomics FC 500 flow cytometer (Beckman Coulter) appointed with argon laser (488 nm). Two-color analysis of apop-

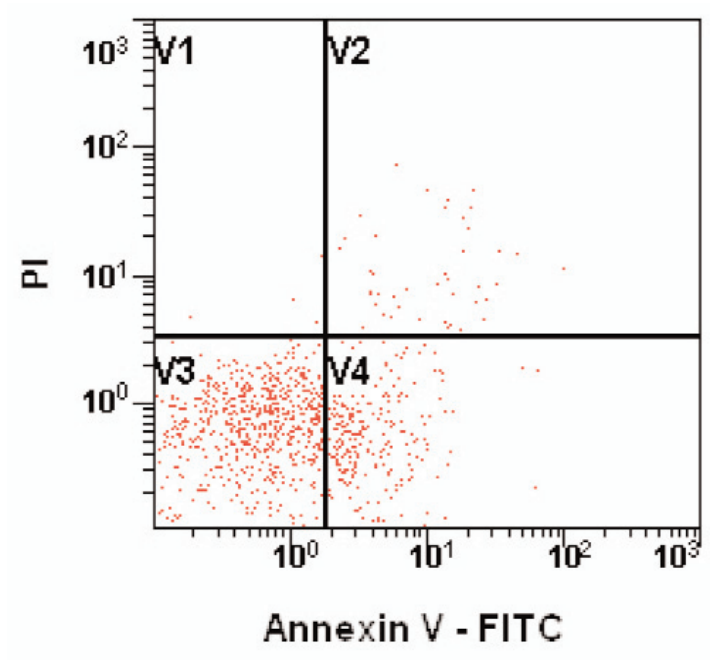

Fig. 1. Example of dot plot presenting AnnexinV/PI staining within mononuclear cells's population. V1 region -PI positive/Annexin $\mathrm{V}$ negative dead cells, V2 -PI positive/Annexin V positive late apoptotic cells, V3 -PI negative/Annexin V negative alive cells, V4 -PI negative /Annexin V positive early apoptotic cells.

tosis within the mononuclear cell population was performed. Fluorescence compensation on the flow cytometer was set to minimize overlap of the fluorescein isothiocyanate (FITC) andPI signals. A total of 20000 events were acquired for each sample. Analysis was based on gating a subpopulation of cells by forward scatter (FS) versus side scatter (SS). Mononuclear cells were analyzed with the protocol of FL1 (Annexin V-FITC) and FL3 (PI) fluorescence. Annexin $\mathrm{V}(+) / \mathrm{PI}(-)$ cells were characterized as early apoptotic, Annexin $\mathrm{V}(+) / \mathrm{PI}(+)$ as late apoptotic and Annexin $\mathrm{V}(-) / \mathrm{PI}(+)$ as dead (Fig. 1).

Statistical analysis. Results are presented as mean \pm SD. Statistical analysis was performed by using the Mann-Whitney $U$ test for unpaired data and Wilcoxon test for paired data. A "p" value of less than 0.05 was considered significant.

\section{Results}

\section{Early apoptosis in lymphocytes from asthmatic children}

The percentage of Annexin $\mathrm{V}$ positive lymphocytes served as a marker of early apoptosis. In unstimulated sample $21.09 \pm 11.20 \%$ cells were characterized as Annexin $\mathrm{V}$ positive/PI negative. After stimulation with antiCD95 Annexin V positive/PI negative cells constituted $18.72 \pm 9.42 \%$ of cells. The difference between percentage of early apoptosis of stimulated and unstimulated cells was not significant (Fig. 2).

\section{Early apoptosis in lymphocytes from healthy children}

In unstimulated sample $11.69 \pm 6.70 \%$ cells were characterized as Annexin $\mathrm{V}$ positive/PI negative. In the sample stimulated with antiCD95 $16.54 \pm 2.98 \%$ of cells were Annexin V positive/PI negative. The result 

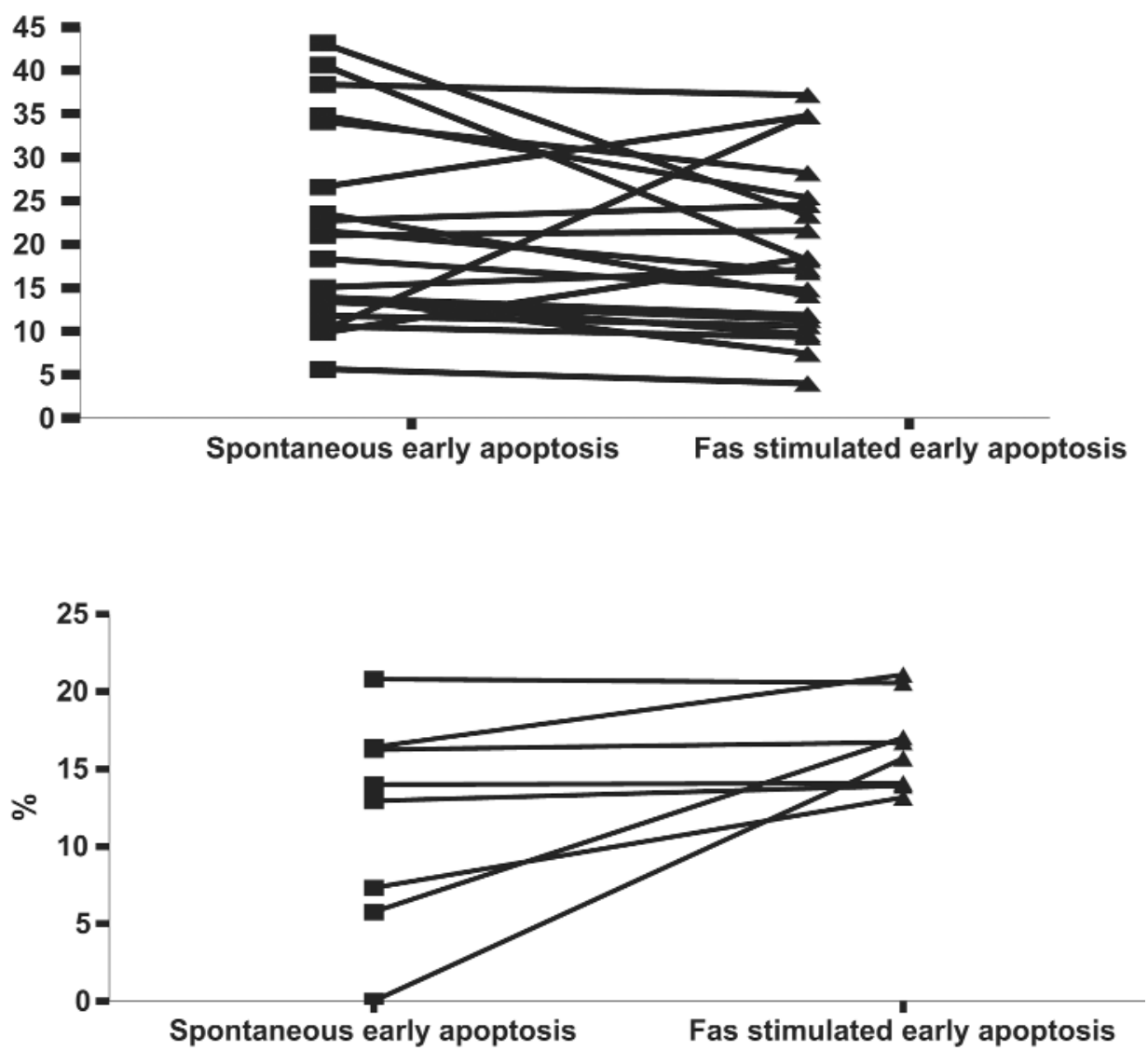

Fig. 2. The percentage of cells stained with Annexin V in asthmatic children, differences between stimulated and not stimulated samples were not significant $\mathrm{p}>0.05$.
Fig. 3. The percentage of cells stained with Annexin V in healthy children, differences between stimulated and not stimulated samples were statistically significant $\mathrm{p}<0.05$.

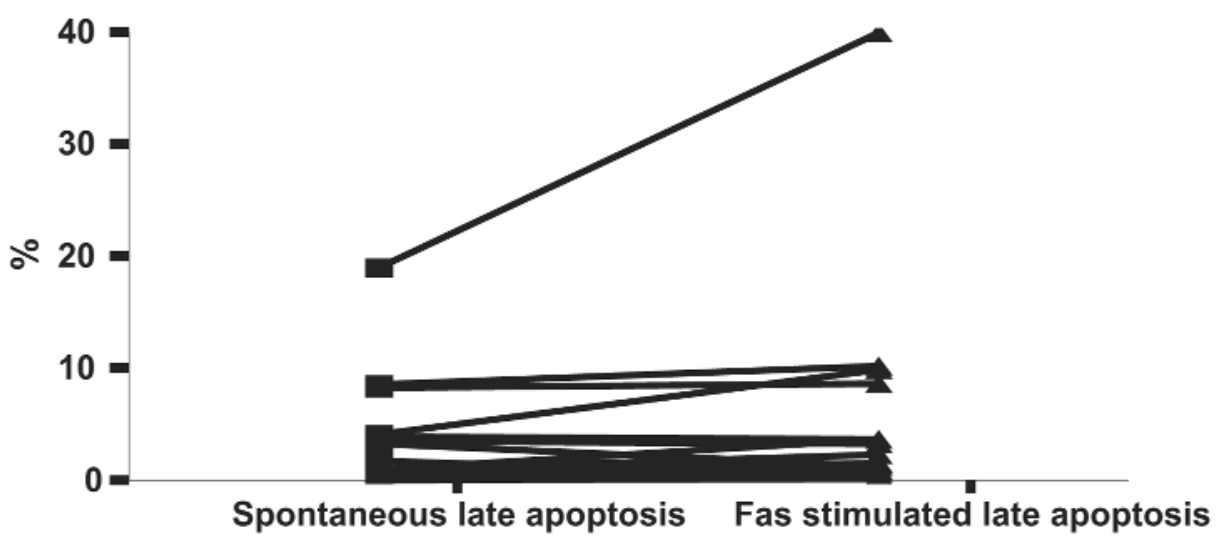

Fig. 4. The percentage of cells stained with Annexin V and Propidium iodide in asthmatic children, differences between stimulated and not stimulated samples were statistically significant $\mathrm{p}<0.05$.

was significantly higher in comparison with unstimulated cells $(\mathrm{p}=0.02)$ (Fig. 3).

\section{Late apoptosis in lymphocytes from asthmatic children}

The annexin $\mathrm{V}$ positive/PI positive cell were considered as being in advanced apoptosis. In unstimulated sample median of cells characterized as Annexin V positive/PI positive was $0.83 \%$ (range $0-18.96 \%$ ). In the sample stimulated with antiCD95 Annexin V positive/PI positive posed $1.47 \%$ (range 0.11 -
$39.92 \%)$ cells. The differences are statistically significant, $\mathrm{p}=0.03$ (Fig. 4).

\section{Late apoptosis in lymphocytes from healthy children}

In unstimulated samples median percentage of cells Annexin $\mathrm{V}$ positive/PI positive was $0.31 \%$ (range $0-$ $1.13 \%$ ). In the samples stimulated with antiCD95, Annexin V positive/PI positive cells constituted $1.35 \%$ (range $0.15-8.6 \%$ ) cells. The differences are statistically significant, $\mathrm{p}=0.02$ (Fig. 5). 


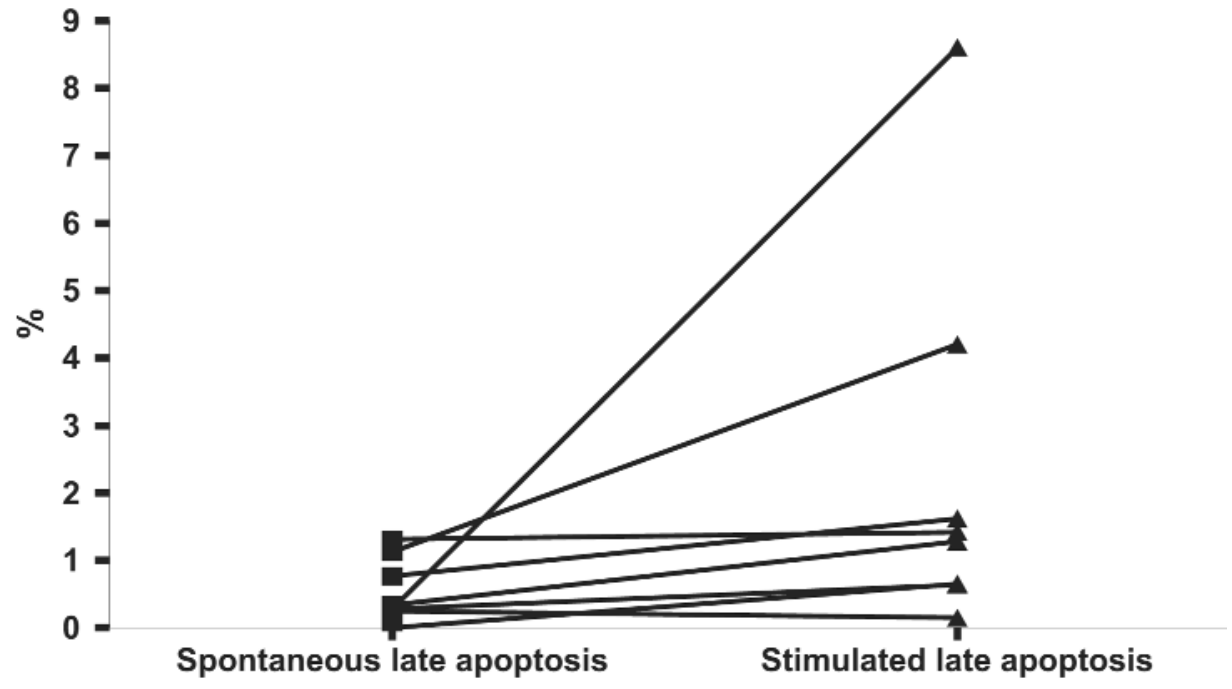

Fig. 5. The percentage of cells stained with Annexin V and Propidium iodide in asthmatic children, differences between stimulated and not stimulated samples were statistically significant $\mathrm{p}<0.05$.

\section{Differences in late apoptotic cells rate between lymphocytes from healthy and asthmatic chil- dren}

Increase of annexin $\mathrm{V}$ positive/PI positive cell percentage served as a marker of advanced apoptosis process. The percentage of cells annexin $\mathrm{V}$ positive increased in asthmatic children (median $0.44 \%$, range from $-1.98 \%$ to $+20.96 \%$ ). Comparably, in non asthmatic increased percentage of cells Annexin V positive was observed (median $0.75 \%$, from $-0.1 \%$ to $+8.32 \%$ ). The differences are not statistically significant.

\section{The percentage of necrotic lymphocytes from healthy and asthmatic children.}

The propidium iodide positivity served as a marker of cell necrosis. The percentage of lymphocytesPI positive from asthmatic was following: median $6.8 \%$, (range: from decrease of $8.26 \%$, to increase of $30.76 \%$ ). Comparably, in non asthmaticPI positive lymphocytes constituted of $11.69 \%$ (median), range $1.03 \%-19.59 \%$. The differences between asthmatic and non-asthmatics were not statistically significant.

\section{Discussion}

An important factor leading to Th2 lymphocytes predomination in atopic patients might be the resistance of lymphocytes to Fas stimulated apoptosis $[5,6]$. In vitro stimulation with antiCD95 monoclonal antibody allows to assess apoptosis resistance [5]. Annexin V/PI staining is proved to be sensitive assay for apoptosis detection. Annexin V binds to externalized phosphatidylserine, marker of early apoptosis.PI flows into cells with broken plasma membrane and binds to DNA and RNA [7-9].
Apoptosis (programmed cell death) is a crucial process in every cellular system $[8,10]$. It participates in tissue development, regulation of immunological system or autoimmune diseases [2,11]. Binding of Annexin V andPI allows to discriminate early, late apoptotic and dead cells. Test can be performed using flow cytometry $[4,9,10]$.

Helper lymphocytes T play aPIvotal role in atopic diseases. Majority of Th0 cells in healthy individuals differentiate to Th1. whereas in atopic individuals majority of Th0 differentiate to Th2 subpopulation. Disturbed $\mathrm{T}$ helper balance is explained by impaired apoptosis of $\mathrm{T}$ cells [3]. It is postulated that Fasmediated apoptosis predominate within CD4+ lymphocytes population [2]. Our results confirm hypothesis, that apoptotic process of lymphocytes from asthmatic patients is impaired. Similar observation was confirmed by Hanzaoui et al. They analysed the percentage of apoptotic cells in sputum from asthmatic subjects. These authors discovered that the percentage of apoptotic lymphocytes in sputum from asthmatics is lower than in healthy or COPD patients [1]. Our results are in the line with these observations.

In our study the lymphocytes from asthmatic and healthy children were stimulated with antiCD95 monoclonal antibody to assess if decreased number of apoptotic lymphocytes is a result of Fas-mediated apoptosis' resistance. We investigated whether the change of apoptotic cells ratio after stimulation with antiCD95 monoclonal antibody is observed in children with asthma comparing to healthy children. Obtained results indicate that lymphocytes from atopic individuals are resistant to Fas stimulation. The comparable results were obtained by Jayaraman et al. [5]. They suggested that lymphocytes $\mathrm{T}$ in asthmatic patients are partially unable to get activated in 
antigen mediated pathway. It is postulated that mainly Fas- triggered pathway is impaired. Apoptosis induced by $\gamma$-irradiation, mitogens or ceramid action is not weakened. It has to be pointed that ability to initiate apoptosis seems not to be limited by the expression of Fas receptors, because it is similar in lymphocytes from healthy and asthmatic individuals [5]. Varadhachary et al. also pointed to Th2 apoptosis resistance [6]. It is also postulated that level of caspase 8 cleavage within Th2 subpopulation is decreased in comparison with Th1 subpopulation. Increased expression of Fas-associated phosphatase (FAP-1), which inhibits caspase cleavage, plays a key role [12].

Investigations performed by other groups were concentrated on the relation between Th2 predomination in atopic individuals and disturbed Th1 vs Th2 apoptosis. Akkoc et al. suggests that Th1 lymphocytes are more sensitive to Fas mediated programmed cell death than Th2 [13]. The same suggestion appears in Zhang's paper [14]. Mechanism which might be engaged in impaired apoptosis process is increased expression of $\mathrm{Fas}$ and Fas ligand within Th1 lymphocytes when compared with Th2 subpopulation. This finding is contradictory to Yajaraman thesis, who postulated that level of Fas expression does not differ between asthmatic and non-asthmatic populations [5]. It is proposed that IFN- $\gamma$ produced by Th1 cells influences caspases expression and sensitizes cells to the apoptosis. To confirm that hypothesis Akkoc et al. proved that absence of IFN- $\gamma$ protects Th1 lymphocytes against Fas - mediated apoptosis [13].

Although we did not compare sensitivity of Th1 and Th2 cells to Fas stimulation, but we have shown decreased percentage of apoptotic lymphocytes from asthmatics in comparison with controls after stimulation with antiCD95.

\section{Conclusions}

Performed research indicates that apoptosis resistance is an inherent feature of asthma. Resistance to Fasmediated apoptosis of lymphocytes may play an important role in the impaired immunoregulation in atopic diseases.

\section{References}

[1] Hamzaoui A, Hamzaoui K, Salah H, Chabbou A. Lymphocytes apoptosis in patients with acute exacerbation of astma. Mediators Inflamm. 1999;8:237-243.

[2] Siegel RM, Fleisher TA. The role of Fas and related death receptors in autoimmune and other disease states. J Allergy Clin Immunol. 1999;103(5):729-738.

[3] Dzienis K, Tryniszewska E, Kaczmarski M. Zaburzenia równowagi immunologicznej subpopulacji Th1 i Th2 oraz rola ich wybranych cytokin w atopowym zapaleniu skóry. Post Dermatol Alergol. 2006;XXIII(2):88-93.

[ 4] Podhorecka M, Bakalczuk G, Jakiel G, Roliński J. The flow cytometry study of Annexin V binding by human spermatozoa - is it a marker of apoptosis? Centr Eur J Immunol. 2003; 28(1):19-22.

[ 5] Jayaraman S, Castro M, O'Sullivan M, Bragdon MJ, Holtzman MJ. Resistance to Fas-mediated T cell apoptosis in asthma. J Immunol. 1999;162:1717-1722.

[ 6] Varadhachary AS, Peter ME, Perdow SN, Krammer PH, Salgame P. Selective up-regulation of phosphatidylinositol 3'kinase activity in Th2 cells inhibits caspaze- 8 cleavage at the death-inducing complex: a mechanism for Th2 resistance from Fas-mediated apoptosis. J Immunol. 1999;163(9):4772-4779.

[7] Koopman G, Reutelingsperger CP, Kuijten RM, Keehnen RM, Pals ST, van Oers MH. Annexin V for flow cytometric detection of phosphatidylserine expression on B cells undergoing apoptosis. Blood. 1994;84:1415-1420.

[ 8] Ormerod MG. The study of apoptotic cells by flow cytometry. Leukemia. 1998;12:1013-1025.

[9] Bertho AL, Santiago MA, Coutinho SG. Flow cytometry in the study of cell death. Mem Inst Oswaldo Cruz, Rio de Janeiro. 2000;95(3):429-433.

[10] Brodowska A, Leszczyńska M, Starczewski A. Apoptosis in ovarian cells in postmenopausal woman. Folia Histochem Cytobiol. 2007;45(2):99-105.

[11] Ojdana D, Safiejko K, Lipska A, Radziwon P, Dadan J, Tryniszewska E. Effector and memory CD4+ and CD8+ T cells in the chronic infection process. Folia Histochem Cytobiol. 2008;46(4):413-417.

[12] Akdis M, Trautmann A, Klunker S et al. T helper (Th) 2 predominance in atopic diseases is due to preferential apoptosis of circulating memory/ effector Th1 cells. FASEB J. 2003;17: 1026-1035.

[13] Akkoc T, de Koning JA, Ruckert B, Barlan I, Akdis M, Akdis CA. Increased activation-induced cell death of high IFN- $\gamma-$ producing Th1 cells as a mechanism of Th2 predominance in atopic diseases. J Allergy Clin Immunol. 2008;121(3):652-658.

[14] Zhang X, Brunner T, Carter L et al. Unequal death in T helper cell (Th1) and Th2 effectors: Th1. but not Th2. effectors undergo rapid Fas/FasL-mediated apoptosis. J Exp Med. 1997;185(10):1837-1849.

Submitted: 24 April, 2009 Accepted after revision: 25 August, 2009 